\title{
Risk factors analysis and stratification for microscopically positive resection margin in gastric cancer patients
}

\author{
Yuta Kumazu' ${ }^{1}$, Tsutomu Hayashi ${ }^{1 *}$, Takaki Yoshikawa ${ }^{2}$, Takanobu Yamada ${ }^{1}$, Kentaro Hara ${ }^{1}$, Yota Shimoda ${ }^{1}$, \\ Masato Nakazono ${ }^{1}$, Shinsuke Nagasawa', Manabu Shiozawa', Soichiro Morinaga', Yasushi Rino ${ }^{3}$, \\ Munetaka Masuda ${ }^{3}$, Takashi Ogata ${ }^{1}$ and Takashi Oshima ${ }^{1}$
}

\begin{abstract}
Background: Cancer cells are often found postoperatively at surgical resection margins (RM) in patients with gastric cancer because of submucosal infiltration or hesitation to secure adequate RM. This study was designed to evaluate risk factors for microscopic positive RM and to clarify which patients should undergo intraoperative frozen section diagnosis (IFSD).

Methods: Patients who underwent R0/1 gastrectomy for gastric adenocarcinoma between 2000 and 2018 in a single cancer center in Japan were studied. We divided the patients into a positive RM group and negative RM group according to the results of definitive histopathological examinations. We performed multivariate analysis to analyze risk factors for positive RM by and used the identified risk factors to risk stratify the patients.

Results: A total of 2757 patients were studied, including 49 (1.8\%) in the positive RM group. The risk factors significantly associated with positive RM were remnant gastric cancer (odds ratio [OR] 4.7), esophageal invasion (OR 6.3), tumor size $\geq 80 \mathrm{~mm}$ (OR 3.9), and a histopathological diagnosis of undifferentiated type (OR 3.6), macroscopic type 4 (OR 3.7), or pT4 disease (OR 4.6). On risk stratification analysis, the incidence of positive RM was $0.1 \%$ without any risk factors, increasing to $0.4 \%$ with one risk factor, $3.1 \%$ with two risk factors, $5.3 \%$ with three risk factors, $21.3 \%$ with four risk factors, and $85.7 \%$ with five risk factors.
\end{abstract}

Conclusions: The risk of macroscopically positive RM increased in patients who have risk factors. IFSD should be performed in patients who have four or more risk factors.

Keywords: Resection margins, Gastric cancer, Risk factors, Intraoperative frozen section, Gastrectomy

\section{Background}

Gastric cancer, a leading cause of cancer-related death worldwide, remains the fourth most common malignancy [1]. Complete tumor removal is essential to effectively treat resectable gastric cancer. To achieve complete resection, it is necessary to secure a sufficient tumor-free

\footnotetext{
*Correspondence: tsuhayas@ncc.go.jp

'Department of Gastrointestinal Surgery, Kanagawa Cancer Center, 241-8515, Asahiku Nakao 2-3-2, Yokohama, Kanagawa, Japan

Full list of author information is available at the end of the article
}

margin as confirmed macroscopically or endoscopically. However, tumors progress horizontally, sometimes spreading as submucosal infiltration while maintaining an apparently normal mucosa, which can mislead surgeons or endoscopists. Even if surgeons make careful efforts to achieve complete resection with negative margins, tumor cells are occasionally observed in resection margins (RM) on postoperative histological examinations, and such margins are diagnosed as microscopically positive (R1).

(c) The Author(s). 2020 Open Access This article is licensed under a Creative Commons Attribution 4.0 International License, which permits use, sharing, adaptation, distribution and reproduction in any medium or format, as long as you give appropriate credit to the original author(s) and the source, provide a link to the Creative Commons licence, and indicate if changes were made. The images or other third party material in this article are included in the article's Creative Commons licence, unless indicated otherwise in a credit line to the material. If material is not included in the article's Creative Commons licence and your intended use is not permitted by statutory regulation or exceeds the permitted use, you will need to obtain permission directly from the copyright holder. To view a copy of this licence, visit http://creativecommons.org/licenses/by/4.0/ The Creative Commons Public Domain Dedication waiver (http://creativecommons.org/publicdomain/zero/1.0/) applies to the data made available in this article, unless otherwise stated in a credit line to the data. 
The correlation between microscopically positive RM and outcomes in patients with gastric cancer remains an issue of debate [2, 3]. However, several previous studies have reported that microscopically positive RM had an unfavorable impact on survival [4-7]. In other words, decreasing the risk of microscopically positive RM might benefit patients. Intraoperative frozen section diagnosis (IFSD) with a diagnostic accuracy of 93 to $100 \%$ has been used to detect tumor cells at the resection margin [8-10]. Although IFSD can decrease unanticipated positive RM, the procedure requires time, costs, and labor. Therefore, it should be performed in specific patients at high risk for positive RM. Stratification of patients based on the risk of positive RM is meaningful in terms of conserving resources.

The aims of this study were to evaluate risk factors for microscopic positive RM and to clarify which patients should undergo IFSD.

\section{Methods \\ Patients}

This retrospective cohort study examined 2757 patients who underwent surgery for gastric cancer or esophagogastric junction cancer from January 2000 through March 2018 in Kanagawa Cancer Center, Japan. All tumors fulfilled the following criteria: (1) histologically proven adenocarcinoma, (2) R0 or R1 resection, and (3) Gastric cancer and adenocarcinoma of the esophagogastric junction. The exclusion criteria were as follows: (1) stage IV cancer without ascites cytology positive reaction (2) R2 resection, and (3) Type I adenocarcinoma of the esophagogastric junction according to the Siewert classification [11]. Cancer staging was based on the Union for International Cancer Control TNM classification, 7th edition [12].

\section{Surgical procedure}

\section{i) Selection of gastrectomy}

Gastrectomy and lymph node dissection were performed in accordance with the JGCA guidelines [13-15]. In short, distal gastrectomy or proximal gastrectomy was preformed when a sufficient proximal or distal RM could be obtained, if not so, total gastrectomy was performed. In principle, D1 or D1+ lymphadenectomy was indicated for cT1N0 tumors, and D2 lymphadenectomy was indicated for $\mathrm{CT} 2-4$ or $\mathrm{cN}+$ tumors.

\section{ii) Determination of resection line of gastrectomy}

The resection line was determined to secure a tumorfree margin as defined in the Japanese gastric cancer guidelines [15]. In principle, a tumor-free margin larger than $3 \mathrm{~cm}$ was secured in cases of macroscopic type 1 or type 2 advanced cancer, while a tumor-free margin larger than $5 \mathrm{~cm}$ was secured in cases of macroscopic type 3 , type 4 , or type 5 advanced cancer as classified according to the classification of JGCA [16]. If tumor invasion spread across the pylorus or cardia, the resection line was determined as the line expected to be tumor-free on intraoperative macroscopic examination. On the other hand, in early cancer, endoscopic marking with clips was performed as required before surgery to indicate the location of the tumor and resection line.

Finally, surgeons opened specimens of the removed stomachs and confirmed negative RM during operation. If surgeons could not macroscopically confirm that tumor-free margin was enough to meet rules as previously mentioned, IFSD was performed, and additional resection was done as necessary.

\section{Evaluation and statistical analysis}

The patients were divided into a positive RM group and negative RM group on the basis of the microscopic findings of the longitudinal margins on definitive histopathological examinations.

The baseline characteristics were compared between the positive and negative RM groups by Pearson's chisquared tests or Fisher's exact tests for categorical variables, as appropriate, and by the Mann-Whitney U tests for continuous variables. Risk factors for positive RM were analyzed by binomial logistic regression analysis. We used risk factors identified by logistic regression analysis to risk stratify the patients.

IBM SPSS Statistics for Windows, Version 24.0 (IBM Corp. Released 2016. Armonk, N.Y.) software was used for statistical analysis. $P$-values of less than 0.05 were considered to indicate statistical significance.

\section{Results}

\section{Patient characteristics}

The demographic and clinicopathological characteristics of the patients are shown in Table 1. Forty-nine patients (1.8\%) with positive RM were studied. Among the 49 patients, there are no patients who received IFSD, and 27 (55.1\%) had positive proximal RM, 15 (30.6\%) had positive distal RM, and 7 (14.3\%) had positive bilateral RM. There was no case with negative frozen section margins that turned out R1 on postoperative histological examination. Patients in the positive RM group received neoadjuvant chemotherapy (14.3\% vs. $4.5 \%, p=0.007)$ and total gastrectomy $(59.2 \%$ vs. $35.4 \%, p<0.001)$ more frequently than those in the negative RM group. Remnant gastric cancer $(12.2 \%$ vs. $2.5 \%, p=0.002)$ and esophageal invasion $(18.4 \%$ vs. $3.5 \%, p<0.001)$ were more frequent in the positive RM group than in the negative RM group. Tumor size in the positive RM group was larger than 
Table 1 Baseline demographic, clinicopathological characteristics in patients with positive margin (PM) and negative margin (NM). IQR: Interquartile Range; BMI: body mass index; ASA-PS: American Society of Anesthesiologists physical status classification system

\begin{tabular}{|c|c|c|c|c|c|}
\hline & $\mathrm{PM}(n=49)$ & & NM $(n=2708)$ & & $P$ value \\
\hline & Number of patients & $\%$ & Number of patients & $\%$ & \\
\hline Age (Median) (IQR) & $66(55-71)$ & & $65(57-72)$ & & 0.949 \\
\hline Sex & & & & & 0.031 \\
\hline Male & 27 & 55.1 & 1856 & 68.5 & \\
\hline Female & 22 & 44.9 & 852 & 31.5 & \\
\hline BMI (Median) (IQR) & $21.5(19.3-23.5)$ & & $22.0(22.0-24.2)$ & & 0.213 \\
\hline ASA-PS & & & & & 0.847 \\
\hline 1 & 17 & 35.4 & 936 & 34.8 & \\
\hline 2 & 30 & 62.5 & 1718 & 64 & \\
\hline 3 & 1 & 2.1 & 32 & 1.2 & \\
\hline Not available & 1 & & 22 & & \\
\hline Neoadjuvant chemotherapy & & & & & 0.007 \\
\hline Yes & 7 & 14.3 & 122 & 4.5 & \\
\hline No & 42 & 85.7 & 2586 & 95.5 & \\
\hline Surgical approach & & & & & 0.004 \\
\hline Open & 44 & 89.8 & 1918 & 70.8 & \\
\hline laparoscopic & 5 & 10.2 & 790 & 29.2 & \\
\hline Gastrectomy & & & & & $<0.001$ \\
\hline Distal & 18 & 36.7 & 1718 & 63.4 & \\
\hline Proximal & 2 & 4.1 & 31 & 1.1 & \\
\hline Total & 29 & 59.2 & 959 & 35.4 & \\
\hline Thoracotomy & & & & & 0.290 \\
\hline Yes & 1 & 2.0 & 18 & 0.7 & \\
\hline No & 48 & 98.0 & 2690 & 99.3 & \\
\hline Remnant cancer & & & & & 0.002 \\
\hline Yes & 6 & 12.2 & 68 & 2.5 & \\
\hline No & 43 & 87.8 & 2640 & 97.5 & \\
\hline Esophageal invasion & & & & & $<0.001$ \\
\hline Yes & 9 & 18.4 & 94 & 3.5 & \\
\hline No & 40 & 81.6 & 2614 & 96.5 & \\
\hline Tumor size (mm) & & & & & \\
\hline Median (IQR) & $105(71-147)$ & - & $41(26-65)$ & - & $<0.001$ \\
\hline$\geq 80 \mathrm{~mm}$ & 34 & 30.6 & 294 & 10.9 & $<0.001$ \\
\hline$<80 \mathrm{~mm}$ & 15 & 69.4 & 2407 & 89.1 & \\
\hline Histopathological type & & & & & $<0.001$ \\
\hline Differentiated & 5 & 10.2 & 1241 & 45.8 & \\
\hline Undifferentiated & 44 & 89.8 & 1467 & 54.2 & \\
\hline Macroscopic Type & & & & & $<0.001$ \\
\hline Type0 & 1 & 2 & 1652 & 61 & \\
\hline Type1 & 0 & 0 & 82 & 3 & \\
\hline Type2 & 0 & 0 & 313 & 11.6 & \\
\hline Type3 & 13 & 26.5 & 282 & 10.4 & \\
\hline Type4 & 24 & 49 & 101 & 3.7 & \\
\hline
\end{tabular}


Table 1 Baseline demographic, clinicopathological characteristics in patients with positive margin (PM) and negative margin (NM). IQR: Interquartile Range; BMI: body mass index; ASA-PS: American Society of Anesthesiologists physical status classification system (Continued)

\begin{tabular}{|c|c|c|c|c|c|}
\hline & \multicolumn{2}{|l|}{ PM $(n=49)$} & \multicolumn{2}{|l|}{ NM $(n=2708)$} & \multirow[t]{2}{*}{$P$ value } \\
\hline & Number of patients & $\%$ & Number of patients & $\%$ & \\
\hline Type5 & 11 & 22.4 & 278 & 10.3 & \\
\hline pT category & & & & & $<0.001$ \\
\hline $\mathrm{T} 1$ & 0 & 0 & 1578 & 58.3 & \\
\hline $\mathrm{T} 2$ & 4 & 8.2 & 374 & 13.8 & \\
\hline T3 & 5 & 10.2 & 238 & 8.8 & \\
\hline T4 & 40 & 81.6 & 518 & 19.1 & \\
\hline pN category & & & & & $<0.001$ \\
\hline NO & 13 & 26.5 & 1827 & 67.5 & \\
\hline N1 & 4 & 8.2 & 344 & 12.7 & \\
\hline N2 & 7 & 14.3 & 245 & 9 & \\
\hline N3 & 25 & 51 & 292 & 10.8 & \\
\hline pTNM stage & & & & & $<0.001$ \\
\hline । & 2 & 4.1 & 1783 & 65.8 & \\
\hline$\|$ & 11 & 22.4 & 453 & 16.7 & \\
\hline III & 723 & 46.9 & 423 & 15.6 & \\
\hline IV & 13 & 26.5 & 49 & 1.8 & \\
\hline
\end{tabular}

Table 2 Incidence rates of positive resection margin and odds ratios in univariate and multivariate analysis. OR: odds ratio; Cl: confidence interval

Number of positive resection margin (Incidence rate)

Neoadjuvant chemotherapy

No

Yes

Remnant cancer

$\begin{array}{ll}\text { No } & 43(1.6 \%) \\ \text { Yes } & 6(8.1 \%)\end{array}$

Esophageal invasion

$\begin{array}{ll}\text { No } & 41(1.5 \%) \\ \text { Yes } & 8(7.8 \%)\end{array}$

Tumor size

$\begin{array}{ll}<80 \mathrm{~mm} & 15(0.6 \%) \\ \geq 80 \mathrm{~mm} & 34(10.4 \%)\end{array}$

Histopathological type

Differentiated

$$
5(0.4 \%)
$$

Undifferentiated

$44(2.9 \%)$

Macroscopic Type

Other than Type4

Type4

$25(0.9 \%)$

24 (19.2\%)

PT category

$\begin{array}{ll}\text { T1-3 } & 9(0.4 \%) \\ \text { T4 } & 40(7.1 \%)\end{array}$

\section{Univariate OR}

(95\% Cl)

1.0

$3.5(1.5-8.0)$

1.0

$5.41(2.2-13.1)$

1.0

$5.42(2.4-11.8)$

1.0

$18.60(10.01-34.56)$

1.0

7.44 (2.9-18.8)

1.0

$25.02(13.8-45.3)$

1.0

$18.6(8.9-38.6)$

\section{$P$-value}

Multivariate OR

(95\% Cl)

1.0

$0.7(0.2-1.9)$

0.593

0.002

1.0

$4.7(1.6-13.3)$

0.003

$<0.001$

1.0

$6.3(2.45-16.5)$

$<0.001$

$<0.001$

1.0

$3.9(1.78-8.7)$

0.001

$3.6(1.3-10.0)$

$3.7(1.7-8.0)$

0.001

$4.6(1.9-10.9)$

$<0.001$ 
that in the negative RM group (105 mm vs. $41 \mathrm{~mm}, p<$ 0.001 ). The proportions of tumors with undifferentiated type of histopathology $(89.8 \%$ vs. $54.2 \%, p<0.001)$ and macroscopic type 4 ( $49 \%$ vs. $3.7 \%, p<0.001$ ) were higher in the positive RM group than in the negative RM group. Patients in the positive RM group had more advanced tumors in terms of pT category, pN category, and pTNM stage. No patient had $\mathrm{pT} 1$ tumors in the positive RM group.

\section{Incidence rates and odds ratios of risk factors}

Table 2 shows the incidence rates and odds ratios of risk factors for positive RM on univariate and multivariate analyses. The incidence rates of positive RM were higher than $10 \%$ in patients who had tumor measuring $\geq 80 \mathrm{~mm}$ or macroscopic type 4 disease (10.4, 19.2\%, respectively). On multivariate analysis, the independent significant risk factors associated with the incidence of positive RM were remnant gastric cancer (odds ratio [OR] 4.7, 95\% CI 1.6-13.3), esophageal invasion (OR 6.3, 95\% CI 2.416.5), tumor size $\geq 80 \mathrm{~mm}$ (OR $3.9,95 \%$ CI 1.7-8.7), undifferentiated type of histopathology (OR 3.6, 95\% CI 1.3-10.0), macroscopic type 4 (OR 3.7, 95\% CI 1.7-8.0), and pT4 (OR 4.6, 95\% CI 1.9-10.9).

\section{Patient risk stratification}

The identified six risk factors for positive RM on multivariate analysis were used to risk stratify the patients (Table 3). In patients who had no risk factors for positive $\mathrm{RM}$, incidence rate of positive RM was $0.1 \%$. The incidence rate increased to $0.4 \%$ with one risk factor, $3.1 \%$ with two risk factors, $5.3 \%$ with three risk factors, $21.3 \%$ with four risk factors and $85.7 \%$ with five risk factors. No patient had all six risk factors. The incidence of positive RM increased progressively with an increase in the number of risk factors. The presence of three or more risk factors was associated with a significant increase in the odds ratio.

\section{Discussion}

The incidence of positive RM in the entire cohort was not high (1.8\%), as compared with that in previous studies evaluating macroscopically positive RM in patients with gastric cancer $(1.8-8.2 \%)[4-7,17]$. The results suggest that our surgical procedures and methods for evaluating appropriate resection lines were at high levels. Nevertheless, surgeons misdiagnosed the resection lines of specimens as being tumor-free, despite the fact that tumor cells remained. Therefore, to prevent unexpected microscopically positive RM, resection with wider excision or IFSD should be performed in cases with a high risk of positive RM.

Our study showed that remnant gastric cancer, esophageal invasion, a tumor size of $\geq 80 \mathrm{~mm}$, undifferentiated type of histopathology, macroscopic type 4, and pT4 were risk factors for positive RM in patients with gastric cancer. Moreover, the risk of positive RM increased in patients with three or more of those risk factors. In particular, owing to high-risk associated with four (21.3\%) or five factors (85.7\%), IFSD should be considered in patients who have four risk factors and is mandatory in patients who have five risk factors. On the other hand, patients without any risk factors do not have to undergo IFSD, because the incidence rate of positive RM is extremely low $(0.1 \%)$.

Previous studies have similarly reported that advanced $\mathrm{T}$ category, advanced $\mathrm{N}$ category, total gastrectomy, larger tumor, EGJ location, diffuse histology, and linitis plastica, which is also referred to as macroscopic type 4, $[3,18,19]$ are risk factors for positive RM. On the basis of these studies, we chose candidate risk factors for preoperatively predicting clinicopathological features. We did not adopt $\mathrm{N}$ category as one of the risk factors because it was not appropriate to substitute $\mathrm{pN}$ for $\mathrm{cN}$ owing to the low preoperative diagnostic accuracy (63.6\%) [20]. Remnant gastric cancer, which remains an unknown risk factor for positive RM in previous studies, was more frequent in the PM group of our study and was therefore adopted as a risk factor for remnant gastric cancer. Finally, six clinicopathological features were identified as risk factors on multivariate analysis in our study, although the factors other than remnant cancer have been reported previously. An innovation of our

Table 3 Risk stratification. Incidence rate of positive resection margin by each number of the risk factors

\begin{tabular}{cllll}
\hline & $\begin{array}{l}\text { Number of positive resection margin } \\
\text { (Incidence rate) }\end{array}$ & Univariate OR & 95\% Cl & P value \\
\hline Risk factors & & & $0.005-0.277$ \\
0 & $1 / 956(0.1 \%)$ & 0.038 & $0.053-0.342$ & 0.001 \\
1 & $5 / 1242(0.4 \%)$ & 0.135 & $0.96-3.93$ & 0.001 \\
2 & $10 / 325(3.1 \%)$ & 1.94 & $1.51-7.81$ & 0.003 \\
3 & $7 / 132(5.3 \%)$ & 3.44 & $13.2-45.3$ & $<0.001$ \\
4 & $20 / 94(21.3 \%)$ & 24.5 & $44.4-3203.8$ & $<0.001$ \\
\hline
\end{tabular}

OR Odds ratio, $\mathrm{Cl}$ Confidence interval 
study was to stratify patients who have risk factors and to show how often microscopically positive RM occurred in patients with such risk factors. To our knowledge, no previous study has reported on risk stratification of positive RM in patients with gastric cancer.

Our study had some limitations that should be taken into consideration when interpreting the results. First, we used the pathological $\mathrm{T}$ category, not the clinical $\mathrm{T}$ category, as an indicator of the invasion depth of tumor. There were no pT1 tumors with positive RM in our study. To utilize this result, accurate preoperative diagnosis is essential. The preoperative diagnosis of cT1 gastric cancer is reported to have 92.4 to $95.4 \%$ accuracy [21-23]. The invasion depth was underestimated in 4.6 to $7.6 \%$ of the patients, who actually had advanced cancer. If the tumor is diagnosed to be being somewhat shallower than the actual depth, the actual resection margin distance would be shorter than the essential margin, which suggests that the incidence rate of positive RM may increase.

A second limitation was that we could not evaluate the margin distance between the tumor and resection line, which was shown to be a risk factor in other studies [18]. Risk stratification in our study was useful for preoperatively estimating the risk of positive RM and for deciding whether IFSD should be performed. However, the estimated risk would change depending on the actual secured margin distance. A multicenter Italian study reported that a RM distance of less than $2 \mathrm{~cm}$ was a risk factor for T1 tumors, and a RM distance of less than 3 $\mathrm{cm}$ was a risk factor for $\mathrm{T} 2$ to $\mathrm{T} 4$ Lauren intestinal pattern tumors [19]. The required margin distance should be evaluated in patients who have high-risk factors for positive RM in future studies.

\section{Conclusions}

In conclusion, patients with gastric cancer who have four or more risk factors from among remnant gastric cancer, esophageal invasion, tumor size $\geq 80 \mathrm{~mm}$, undifferentiated type of histopathology, macroscopic type 4 , and pT4, have a high risk of macroscopically positive RM despite macroscopically negative margins as evaluated on intraoperative examination. In such patients, resection with wider excision should be performed as much as possible, or IFSD should be performed to confirm whether the resection margin is negative or positive.

\footnotetext{
Abbreviations

RM: Resection margin; IFSD: Intraoperative frozen section diagnosis; JGCA: Japanese Gastric Cancer Association; PM: Positive margin; NM: Negative margin; IQR: Interquartile range; BMI: Body mass index; ASAPS: American Society of Anesthesiologists physical status classification system; OR: Odds ratio; Cl: Confidence interval
}

Acknowledgements

Not applicable.

\section{Authors' contributions}

YK, TH, TY1, TY2, KH, YS, MN, SN, MS, SM, YR, MM, TO1 and TO2 contributed to the design and implementation of the research, to the analysis of the results and to the writing of the manuscript. The authors read and approved the manuscript.

Funding

Not applicable.

\section{Availability of data and materials}

We cannot share the data and materials, because the Ethics Committee of Kanagawa Cancer Center Hospital prohibit publication of raw database including patients' clinical data even if identifying/confidential data was not included.

\section{Ethics approval and consent to participate}

This study was conducted in accordance with the Declaration of Helsinki. This study was approved by the Ethics Committee of Kanagawa Cancer Center Hospital, and written informed consent was obtained before surgery from all patients.

\section{Consent for publication \\ Not applicable.}

\section{Competing interests}

The authors declare that they have no competing interests.

\section{Author details}

'Department of Gastrointestinal Surgery, Kanagawa Cancer Center, 241-8515, Asahiku Nakao 2-3-2, Yokohama, Kanagawa, Japan. ${ }^{2}$ Devision of Gastric

Surgery, National Cancer Center Hospital, Chuoku Tsukiji 5-1-1, Tokyo, Japan. ${ }^{3}$ Department of Surgery, Yokohama City University, Kanazawaku Fukuura 3-9, Yokohama, Kanagawa, Japan.

Received: 19 February 2020 Accepted: 12 April 2020

Published online: 07 May 2020

\section{References}

1. Cancer Today. http://gco.iarc.fr/today/data/factsheets/cancers/7-Stomachfact-sheet.pdf. Accessed 3 June 2019.

2. Postlewait LM, Maithel SK. The importance of surgical margins in gastric cancer. J Surg Oncol. 2016;113(3):277-82.

3. Raziee HR, Cardoso R, Seevaratnam R, Mahar A, Helyer L, Law C, et al. Systematic review of the predictors of positive margins in gastric cancer surgery and the effect on survival. Gastric Cancer. 2012;15(Suppl 1):S116-24.

4. Sun Z, Li DM, Wang ZN, Huang BJ, Xu Y, Li K, et al. Prognostic significance of microscopic positive margins for gastric cancer patients with potentially curative resection. Ann Surg Oncol. 2009;16(11):3028-37.

5. Morgagni P, Garcea D, Marrelli D, De Manzoni G, Natalini G, Kurihara H, et al. Resection line involvement after gastric cancer surgery: clinical outcome in nonsurgically retreated patients. World J Surg. 2008;32(12):2661-7.

6. Wang SY, Yeh CN, Lee HL, Liu YY, Chao TC, Hwang TL, et al. Clinical impact of positive surgical margin status on gastric cancer patients undergoing gastrectomy. Ann Surg Oncol. 2009;16(10):2738-43.

7. Liang $Y$, Ding $X$, Wang $X$, Wang B, Deng J, Zhang L, et al. Prognostic value of surgical margin status in gastric cancer patients. ANZ J Surg. 2015;85(9): 678-84

8. Ferreiro JA, Myers $\mathrm{J}$, , Bostwick DG. Accuracy of frozen section diagnosis in surgical pathology: review of a 1-year experience with 24,880 cases at Mayo Clinic Rochester. Mayo Clin Proc. 1995;70(12):1137-41.

9. Spicer J, Benay C, Lee L, Rousseau M, Andalib A, Kushner Y, et al. Diagnostic accuracy and utility of intraoperative microscopic margin analysis of gastric and esophageal adenocarcinoma. Ann Surg Oncol. 2014;21(8):2580-6.

10. Matsusaka S, Nagareda T, Yamasaki H, Kitayama Y, Okada T, Maeda S. Immunohistochemical evaluation for intraoperative rapid pathological assessment of the gastric margin. World J Surg. 2003;27(6):715-8.

11. Siewert JR, Stein HJ. Classification of adenocarcinoma of the oesophagogastric junction. Br J Surg. 1998;85(11):1457-9.

12. Sobin LH WC, Gospodarowicz M. TNM classification of malignant tumors (UICC). 7th edn. New York: Wiley-Blackwell; 2009. 
13. Nakajima T. Gastric cancer treatment guidelines in Japan. Gastric Cancer. 2002;5:1-5.

14. Association. JGC. Japanese gastric cancer treatment guidelines 2010 (ver. 3). Gastric Cancer. 2011;14(2):113-23.

15. Association JGC. Japanese gastric cancer treatment guidelines 2014 (ver. 4). Gastric Cancer. 2017;20(1):1-19.

16. Association JGC. Japanese classification of gastric carcinoma: 3rd English edition. Gastric Cancer. 2011;14 (2):101-112.

17. Cho BC, Jeung HC, Choi HJ, Rha SY, Hyung WJ, Cheong JH, et al. Prognostic impact of resection margin involvement after extended (D2/D3) gastrectomy for advanced gastric cancer: a 15-year experience at a single institute. J Surg Oncol. 2007;95(6):461-8.

18. Blackham AU, Swords DS, Levine EA, Fino NF, Squires MH, Poultsides G, et al. Is Linitis Plastica a contraindication for surgical resection: a multiinstitution study of the U.S. gastric cancer collaborative. Ann Surg Oncol. 2015;23(4):1203-11.

19. Bissolati M, Desio M, Rosa F, Rausei S, Marrelli D, Baiocchi GL, et al. Risk factor analysis for involvement of resection margins in gastric and esophagogastric junction cancer: an Italian multicenter study. Gastric Cancer. 2017;20(1):70-82

20. Fukagawa T, Katai H, Mizusawa J, Nakamura K, Sano T, Terashima M, et al. A prospective multi-institutional validity study to evaluate the accuracy of clinical diagnosis of pathological stage III gastric cancer (JCOG1302A). Gastric Cancer. 2018;21(1):68-73.

21. Sano T, Okuyama Y, Kobori O, Shimizu T, Morioka Y. Early gastric cancer. Endoscopic diagnosis of depth of invasion. Dig Dis Sci. 1990;35(11):1340-4.

22. Yanai H, Matsumoto $\mathrm{Y}$, Harada T, Nishiaki M, Tokiyama H, Shigemitsu T, et al. Endoscopic ultrasonography and endoscopy for staging depth of invasion in early gastric cancer: a pilot study. Gastrointest Endosc. 1997;46(3):212-6.

23. Tsujimoto H, Sugasawa H, Ono S, Ichikura T, Yamamoto J, Hase K. Has the accuracy of preoperative diagnosis improved in cases of early-stage gastric cancer? World J Surg. 2010;34(8):1840-6.

\section{Publisher's Note}

Springer Nature remains neutral with regard to jurisdictional claims in published maps and institutional affiliations.

Ready to submit your research? Choose BMC and benefit from:

- fast, convenient online submission

- thorough peer review by experienced researchers in your field

- rapid publication on acceptance

- support for research data, including large and complex data types

- gold Open Access which fosters wider collaboration and increased citations

- maximum visibility for your research: over $100 \mathrm{M}$ website views per year

At $\mathrm{BMC}$, research is always in progress.

Learn more biomedcentral.com/submissions 